\title{
Genetic influences on insight problem solving: the role of catechol-O-methyltransferase (COMT) gene polymorphisms
}

\author{
Weili Jiang, Siyuan Shang and Yanjie Su* \\ Department of Psychology and Beijing Key Laboratory of Behavior and Mental Health, Peking University, Beijing, China
}

\section{OPEN ACCESS}

Edited by:

Kevin Bradley Clark,

University of California Los Angeles,

USA

Reviewed by:

Rolf Verleger,

Universität zu Lübeck, Germany

Manish Saggar

Stanford University, USA

David Quentin Beversdorf,

University of Missouri, USA

*Correspondence:

Yanjie Su

yjsu@pku.edu.cn

Specialty section:

This article was submitted to

Cognition,

a section of the journal

Frontiers in Psychology

Received: 28 July 2015 Accepted: 28 September 2015

Published: 13 October 2015

Citation:

Jiang W, Shang S and Su Y (2015)

Genetic influences on insight problem

solving: the role

of catechol-O-methyltransferase (COMT) gene polymorphisms.

Front. Psychol. 6:1569.

doi: 10.3389/fpsyg.2015.01569
People may experience an "aha" moment, when suddenly realizing a solution of a puzzling problem. This experience is called insight problem solving. Several findings suggest that catecholamine-related genes may contribute to insight problem solving, among which the catechol-O-methyltransferase (COMT) gene is the most promising candidate. The current study examined 753 healthy individuals to determine the associations between 7 candidate single nucleotide polymorphisms on the COMT gene and insight problem-solving performance, while considering gender differences. The results showed that individuals carrying A allele of rs4680 or T allele of rs4633 scored significantly higher on insight problem-solving tasks, and the COMT gene rs5993883 combined with gender interacted with correct solutions of insight problems, specifically showing that this gene only influenced insight problem-solving performance in males. This study presents the first investigation of the genetic impact on insight problem solving and provides evidence that highlights the role that the COMT gene plays in insight problem solving.

Keywords: creativity, insight problem solving, COMT gene, catecholamines, gender differences

\section{INTRODUCTION}

In daily life, people may get stuck with some problems that cannot be solved using regular methods, and suddenly somehow get the solution or an idea, accompanying with a delightful "aha" feeling. This experience is called insight problem solving (Sternberg and Davidson, 1995; Smith and Kounios, 1996; Bowden et al., 2005; Chu and MacGregor, 2011). Insight problem solving, in contrast with other forms of problem solving, is an "all-at-once" process rather than an analytic process or a trial-and-error process, solvers usually cannot report how they get insight solutions. Insight problem solving is critical to individual survival, well-being and prosperity, for it may occur in several domains, from perception to language comprehension, like recognizing an ambiguous object or understanding a joke (Kounios and Beeman, 2014). Moreover, insight problem solving can result in important innovations that contribute to human society development and achievement (Simonton, 2003; Runco, 2004). For example, Archimedes' principle was discovered because of a light flashing in Archimedes' mind when he got into a tub and saw the water overflowing, crying "Eureka". Despite its importance, the underlying biological mechanisms of insight problem solving are not yet completely understood. Insight problem solving is not a unique human capacity - it has also been found in non-human species (Shettleworth, 2012), 
such as chimpanzees (Köhler, 1925) and elephants (Foerder et al., 2011). This suggests that this type of problem solving has deep evolutionary and biological roots. Further, insight problem solving is often regarded as a form of creativity (Friedman and Förster, 2005), and twin studies demonstrate that creativity has genetic underpinnings (Velázquez et al., 2015). Most molecular genetic studies of creativity adopted divergent thinking tasks rather than insight problem tasks (e.g., Reuter et al., 2006; Runco et al., 2011), while these two tasks were used to test two different components of creativity (Lin and Lien, 2013). Taken together, it is essential to investigate the deep genetic influences on insight problem solving, to improve our understanding of insight problem solving and creativity.

Previous cognitive and neuroscience studies of insight problem solving indicate that catecholamines, including dopamine (DA) and norepinephrine (NE), may play a critical role in the cognitive process of insight problem solving (Folley et al., 2003; Heilman et al., 2003; Cai et al., 2009). Insight problem solving benefits from positive mood states, especially those activating positive moods rather than deactivating ones, like happiness (Isen et al., 1987; Baas et al., 2008; Subramaniam et al., 2009). Further, insight problem solving process involves some aspects of executive function, such as working memory (Fleck, 2008; Gilhooly and Fioratou, 2009; Lin and Lien, 2013) and cognitive flexibility (Lin et al., 2014). Meanwhile, both positive moods and executive functions, in turn, are related to the catecholamine levels (Ashby et al., 1999; Chudasama and Robbins, 2006; Hillier et al., 2006; Baas et al., 2008; Subramaniam et al., 2009; Cools and D'Esposito, 2011). Furthermore, findings in psychiatry demonstrate that some kinds of mental states that are associated with DA level can lead to positive consequence in terms of insight problem solving. For instance, schizophrenia, a disease that results from hyperactive DA signal transduction (Davis et al., 1991), is correlated with better insight problem-solving performance (Karimi et al., 2007).

Hence, genes involved in catecholamine transmission are likely to be the candidate genes that may contribute to insight problem solving. Of the catecholamine-related genes, catechol$O$-methyltransferase (COMT) gene is the most investigated gene, which encodes the COMT enzyme. The COMT enzyme is the most important catabolic enzymes, especially in the prefrontal cortex, which degrades the catecholamines (Chen et al., 2004). Through encoding COMT enzyme, COMT genes influence the level of DA and NE.

The COMT gene is located on chromosome 22q11 in humans. The greatest variance of COMT activity is explained by a common single nucleotide polymorphism (SNP) Val158Met (rs4680). The $\mathrm{G} \longrightarrow \mathrm{A}$ transition makes amino acid valine (Val) be replaced by methionine (Met), and the activity of COMT enzyme will decrease by approximately $35-50 \%$ (Lachman et al., 1996; Chen et al., 2004). As a result, G/G (Val/Val) gene carriers have the highest activity of COMT enzyme and the lowest level of DA and NE. Previous studies used divergent thinking tasks to investigate the genetic influences on creativity, and found that the A allele of rs4680 is associated with better creativity (Runco et al., 2011; Zhang et al., 2014a). For example, using the Instance Task and Realistic Creative Problem Solving, researchers found that individuals with $\mathrm{A} / \mathrm{A}$ genotype showed better divergent thinking (Runco et al., 2011). And insight problem solving has high correlation with divergent thinking (Gilhooly and Murphy, 2005; DeYoung et al., 2008; Lee and Therriault, 2013). On the other hand, studies have found that carriers of the A/A genotypes in rs4680 have the best performance on executive functions, like working memory and cognitive flexibility (Egan et al., 2001; Goldberg et al., 2003; Witte and Flöel, 2012), which play an important role in insight problem solving (Fleck, 2008; Gilhooly and Fioratou, 2009; Lin and Lien, 2013; Lin et al., 2014). For example, Barnett et al. (2007b) conducted a meta-analysis of a specific executive function task - the Wisconsin Card Sorting Test and found that individuals with the $\mathrm{A} / \mathrm{A}$ genotype performed better in the Wisconsin Card Sorting Test than those with the G/G genotype. Furthermore, from the psychiatric perspective, in Chinese population, individuals with genotype G/G show the lowest Schizotypal Personality Questionnaire scores (Ma et al., 2007), which have been shown to be related to decreased insight problem-solving performance (Karimi et al., 2007). Besides the COMT gene rs4680, there are other COMT gene functional SNPs that might have an impact on insight problem solving. For instance, SNP rs5993883 is associated with divergent thinking (Zhang et al., 2014a).

In addition, gender may moderate the relation between the COMT gene and insight problem solving. COMT effects are not the same between different genders (Harrison and Tunbridge, 2008). For men, COMT activity in prefrontal cortex is $17 \%$ higher than that in women (Chen et al., 2004), and the COMT gene has a greater impact in men. For example, the A allele of rs4680 was associated with better working memory only in men, not in women (Barnett et al., 2007a).

In all, insight problem solving is a very important creative ability found not only in humans but also in non-human animals. The COMT gene had been assessed with divergent thinking tasks, but not with this kind of creative task. In addition, studies mainly focus on a common SNP of the COMT gene, rs4680. So the present study aimed to investigate a possible association between insight problem solving and the COMT gene, including several SNPs rather than only rs4680 to look at the broader picture of COMT gene influences, and considering gender as a potential moderator.

\section{MATERIALS AND METHODS}

\section{Participants}

The sample comprised 753 healthy Chinese high-school students (516 females and 237 males) in Southwest China. The mean age was 16.54 years, $S D=0.70$ years, range from 14.33 to 19.14 years. The study was approved by the local ethics committees of Peking University. All participants gave written informed consent after a description and an explanation of the study. Upon completion of all tests, reimbursements were given for their participation. Participants first completed a paper-and-pencil measurement, and then their buccal cells were collected for genotyping. 


\section{Assessment of Insight Problem Solving}

Participants were required to solve 13 classic, pure insight problems, which were adapted from prior published researches (Dow and Mayer, 2004; Chiu et al., 2008; DeYoung et al., 2008). Pure insight problems can only be solved by insight solution rather than trial-and-error solution. Problems without confusion or eliminate were chosen, which covered a range of difficulty. Example 1: Fang and Hong were born on the same day of the same month of the same year to the same mother and the same father - yet they are not twins. How is that possible? The correct answer is that they are triplets or multiple births. Example 2: There exists an ancient invention still used in the world today, which allows people to see through the wall. What is it? The correct answer is windows. For each problem, participants were given 2 min to solve. After being tested, participants were asked whether they knew the problem and the solution before. Responses were scored for accuracy on unknown problems.

\section{Genotyping}

A saliva swab was obtained from each subject and DNA was extracted using FlexiGene DNA Kit (Qiagen, Valencia, CA, USA). Based on previous studies, seven single polymorphisms in COMT gene (rs2020917, rs737865, rs59938883, rs4633, rs6267, rs4818, and rs4680) were chosen in the Hapmap database ${ }^{1}$ and NCBI SNP database ${ }^{2}$. All these SNPs are reported having an effect on catecholamines, with minor allele frequency $(\mathrm{MAF})>5 \%$. The SNP genotyping work was performed using an improved multiplex ligation detection reaction (iMLDR) technique developed by Genesky Biotechnologies Inc. (Shanghai, China). A multiplex PCR-ligase detection reaction method was used in the iMLDR. For each SNP, the alleles were distinguished by different fluorescent labels of allele-specific oligonucleotide probe pairs. Different SNPs were further distinguished by different extended lengths at the $3^{\prime}$ end. All primers, probes and labeling oligos were designed by and ordered from Genesky Biotechnologies Inc. (Shanghai, China). The raw data was analyzed by GeneMapper 4.1. For quality control, a random

${ }^{1}$ http://hapmap.ncbi.nlm.nih.gov/

${ }^{2}$ http://www.ncbi.nlm.nih.gov/SNP
DNA sample accounting for $5 \%$ was genotyped twice, yielding a reproducibility of $100 \%$.

\section{Statistical Analysis}

First, descriptive statistics were ascertained to examine the distributional properties of the average number of correct solution of insight problems, and how this performance correlated with age. To determine whether the average number of correctly solved insight problems differed by gender, $t$-tests were also employed. Second, Hardy-Weinberg equilibrium, linkage disequilibrium (LD) and haplotype blocks were tested. Third, descriptive statistics for insight problem-solving performance by genotype in females and males were conducted. Finally, the genotype of seven SNPs of the COMT gene and gender interaction with insight problem solving were analyzed using ANCOVA analysis, taking age as a covariate variable. We reported uncorrected $P$-values in the text.

\section{RESULTS}

The average number of correctly answered insight problems was $7.28(S D=2.54$, range $=1-13)$. This outcome significantly correlated with age $(r=0.12, p=0.004)$, and so we controlled for the effect of age in the following analysis. Additionally, we found a gender difference, with males $(M=7.72, S D=2.50)$ showing higher insight problem-solving scores compared to females $(M=7.08, S D=2.54), t(751)=3.24, p=0.001, d=0.25$.

Table 1 summarizes the minor allele frequencies, the number of participants per allelic group, and p-values for the HardyWeinberg equilibrium tests. All seven SNPs were polymorphic with MAF $>5 \%$ and in Hardy-Weinberg equilibrium. Haploview was used to analyze LD and construct haplotype blocks of the studied COMT polymorphisms. Figure 1 shows LD pattern of the seven COMT SNPs. Two haplotype blocks were detected from these seven SNPs using the solid spine of LD algorithm. Block 1 was composed of rs2020917 and rs737865, while block 2 included four SNPs (rs4633, rs6267, rs4818, rs4680).

There were no significant differences in the distribution of the seven SNPs between males and females. Table 2 shows the descriptive statistics for insight problem-solving performance by

TABLE 1 | Gene location, allele, and genotype frequencies of the investigated COMT gene polymorphisms.

\begin{tabular}{|c|c|c|c|c|c|c|c|c|}
\hline $\begin{array}{l}\text { Single nucleotide } \\
\text { polymorphisms (SNP) }^{a}\end{array}$ & Position $^{b}$ & Location & $\begin{array}{c}\text { Allele } \\
\text { (minor/major) }\end{array}$ & Genotype & $n$ & Frequency & $\operatorname{MAF}^{c}(\%)$ & $p-\mathrm{HWE}^{\mathrm{d}}$ \\
\hline rs2020917 & 18308884 & 5'upstream & $\mathrm{T} / \mathrm{C}$ & $\mathrm{CC} / \mathrm{CT} / \mathrm{TT}$ & $386 / 310 / 57$ & $0.513 / 0.412 / 0.076$ & 0.282 & 0.629 \\
\hline rs5993883 & 18317638 & Intron 1 & $\mathrm{G} / \mathrm{T}$ & TT/TG/GG & 278/348/107 & $0.369 / 0.462 / 0.142$ & 0.383 & 0.910 \\
\hline rs4633 & 18330235 & Exon 3 & $\mathrm{~T} / \mathrm{C}$ & $\mathrm{CC} / \mathrm{CT} / \mathrm{TT}$ & $420 / 290 / 43$ & $0.558 / 0.385 / 0.057$ & 0.250 & 0.443 \\
\hline rs6267 & 18330263 & Exon 3 & $T / G$ & GG/GT/TT & $666 / 85 / 2$ & $0.884 / 0.113 / 0.003$ & 0.059 & 0.680 \\
\hline
\end{tabular}

a SNPS are listed down the column in sequential order from the $5^{\prime}$ end to the $3^{\prime}$ end of the sense strand of COMT.

b Physical position is based on NCBI B36.

${ }^{\mathrm{C}} M A F$, minor allele frequency.

$\mathrm{d}_{p}$-HWE, $p$-value of Hardy-Weinberg equilibrium test. 


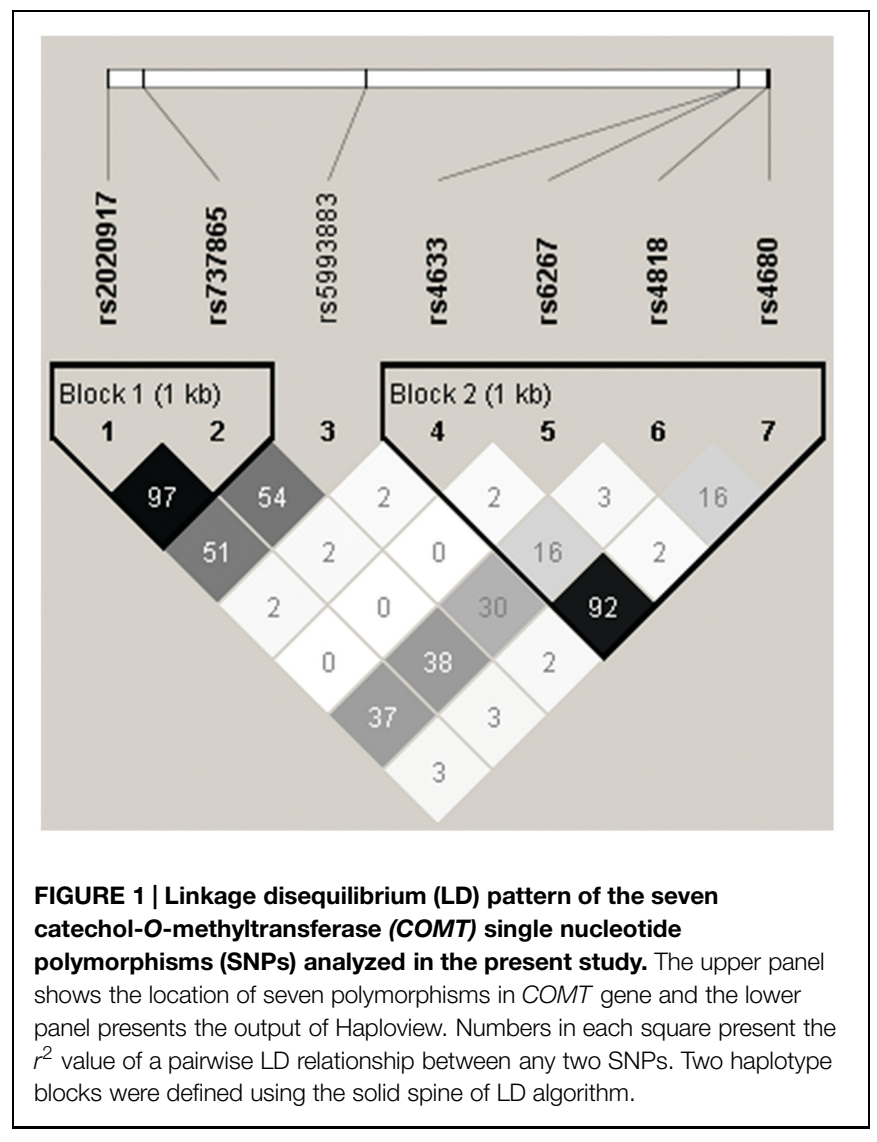

gender and different SNPs. As the number of participants in the least common allele pair was less than 20, for rs2020917, rs737865, rs4633, rs6267, and rs4680, we collapsed the less common homozygote carriers and heterozygote carriers into one group for further ANCOVA analysis. The interactions between the seven SNPs in the COMT gene and gender on insight problem-solving performance are shown in Table 3. We found that three COMT gene SNPs (rs5993883, rs4633, rs4680) displayed an impact on insight problem solving, whilst the other four SNPs (rs2020917, rs737865, rs6267, rs4818) in the COMT gene had no significant effect on insight problem solving.

Specifically, there was a significant main effect of COMT rs4633 on insight problem-solving tasks, $F(1,708)=4.11$, $p=0.043, \eta^{2}=0.006$; $\mathrm{T}$ allele (TT and CT) carriers had higher insight problem-solving scores than those with CC genotype $(d=0.15)$. Similarly, there was also a significant effect of COMT rs4680 on insight problem-solving performance, $F(1,708)=5.11$, $p=0.024, \eta^{2}=0.007 ; \mathrm{A}$ allele (AA and GA) carriers scored higher in insight tasks than those with GG genotype $(d=0.18)$.

There was a significant interaction between COMT rs5993883 and gender on insight problem-solving tasks, $F(2,687)=3.83$, $p=0.022, \eta^{2}=0.011$ (see Figure 2). Simple effects tests showed that only in males did these three genotype carriers differ in insight problem-solving performance [Bonferroni test, $F(2,687)=3.19, p=0.042, \eta^{2}=0.009$ ]. Specifically, TT genotype carriers showed a better insight problem-solving performance than GG carriers only for males ( $p=0.043, d=0.58$ ). Further, due to this interaction the general advantage of males vs. females was restricted to TT genotype carriers where males with TT genotype scored higher than females with TT [Bonferroni test, $\left.F(2,687)=9.97, p=0.002, \eta^{2}=0.014, d=0.41\right]$. Because of the large differences in sample sizes, with only 29 males carrying G/G genotypes, far less than other gene-gender-combination groups, to confirm the effect, we randomly chose 29 samples from the other five groups to conduct another ANCOVA analysis. The results didn't change, for there still exists a significant interaction between genotype of rs5993883 and gender, $F(2,168)=4.63$, $p=0.011, \eta^{2}=0.052$. Although we found three COMT gene SNPs (rs5993883, rs4633, rs4680) displayed an impact on insight problem solving, none of the reported significance survived correction for multiple comparisons using false discovery rate method.

\section{DISCUSSION}

The present study tested the association between insight problem-solving performance and the COMT gene including seven SNPs, and found that COMT rs4680 and COMT rs4633 were correlated with insight problem solving. Moreover, there was a gender difference in the association between the COMT gene and insight problem solving, with only male carriers of the TT genotype in COMT rs5993883 showing better insight tasks performance than GG carriers, an effect not found in females. These findings supported the relationship between insight problem solving and the COMT gene, although the results should be interpreted cautiously. After all, at significant levels corrected for multiple comparisons, none of COMT gene variants influenced insight problem solving. However, based on previous studies, there were some indirect supporting evidences for the association between the COMT gene and insight problem solving. Combined with these evidence, the result of these multiple comparisons here might indicate that the effect size of this association is not large enough, although we couldn't rule out the possibility that the association between the COMT gene and insight problem solving are not to be found.

COMT rs4680, the most commonly studied COMT gene polymorphisms, was found to be correlated with insight problem solving, which suggested that A allele carriers had better insight problem-solving abilities. This result is in line with some previous indirect findings that the A allele of COMT rs4680 plays an important role in executive functions like working memory, schizotypy and divergent thinking (Egan et al., 2001; Ma et al., 2007; Runco et al., 2011; Zhang et al., 2014a), which are all correlated with insight problem solving (Karimi et al., 2007; DeYoung et al., 2008; Fleck, 2008). Additionally, rs4633, which has a strong LD with rs4680, also showed an effect on insight problem solving, with $\mathrm{T}$ allele carriers achieving higher insight problem-solving scores. This result was also consistent with previous findings that rs4633 showed a significant association with schizophrenia (Handoko et al., 2005), which has been demonstrated to correlate with insight problem solving (Karimi et al., 2007). For rs5993883, gender moderated its relation with insight problem solving, and rs5993883 had an impact on 
TABLE 2 | Insight problem-solving performance by genotype and gender.

\begin{tabular}{|c|c|c|c|c|c|c|c|}
\hline & & \multicolumn{2}{|c|}{ Total } & \multicolumn{2}{|c|}{ Males } & \multicolumn{2}{|c|}{ Females } \\
\hline & & $n$ & $M(S D)$ & $n$ & $M(S D)$ & $n$ & $M(S D)$ \\
\hline \multirow[t]{3}{*}{ rs2020917 } & $\mathrm{C} / \mathrm{C}$ & 386 & $7.31(2.50)$ & 123 & 7.89 (2.36) & 263 & $7.04(2.51)$ \\
\hline & $\mathrm{C} / \mathrm{T}$ & 310 & $7.21(2.57)$ & 99 & $7.50(2.64)$ & 211 & $7.08(2.54)$ \\
\hline & $\mathrm{T} / \mathrm{T}$ & 57 & $7.46(2.73)$ & 15 & $7.80(2.73)$ & 42 & $7.33(2.75)$ \\
\hline \multirow[t]{3}{*}{ rs737865 } & A/A & 390 & $7.30(2.49)$ & 126 & $7.88(2.34)$ & 264 & $7.03(2.51)$ \\
\hline & $A / G$ & 309 & $7.21(2.58)$ & 96 & $7.50(2.68)$ & 213 & $7.08(2.54)$ \\
\hline & $\mathrm{G} / \mathrm{G}$ & 54 & $7.56(2.74)$ & 15 & $7.80(2.73)$ & 39 & $7.46(2.77)$ \\
\hline \multirow[t]{3}{*}{ rs5993883 } & $\mathrm{G} / \mathrm{G}$ & 107 & 7.22 (2.69) & 29 & $6.90(2.68)$ & 78 & $7.33(2.70)$ \\
\hline & $\mathrm{T} / \mathrm{G}$ & 348 & $7.23(2.55)$ & 108 & $7.50(2.48)$ & 240 & $7.11(2.58)$ \\
\hline & $\mathrm{T} / \mathrm{T}$ & 278 & 7.32 (2.49) & 92 & $8.08(2.41)$ & 186 & $6.95(2.45)$ \\
\hline \multirow[t]{3}{*}{ rs4633 } & $\mathrm{C} / \mathrm{C}$ & 420 & $7.11(2.55)$ & 132 & $7.46(2.51)$ & 288 & $6.95(2.55)$ \\
\hline & $\mathrm{C} / \mathrm{T}$ & 290 & $7.52(2.51)$ & 89 & 7.99 (2.54) & 201 & $7.31(2.48)$ \\
\hline & $\mathrm{T} / \mathrm{T}$ & 43 & $7.33(2.67)$ & 16 & 8.38 (2.03) & 27 & $6.70(2.84)$ \\
\hline \multirow[t]{3}{*}{ rs6267 } & $\mathrm{G} / \mathrm{G}$ & 666 & 7.32 (2.51) & 211 & 7.78 (2.50) & 455 & $7.11(2.50)$ \\
\hline & $\mathrm{G} / \mathrm{T}$ & 85 & $6.94(2.77)$ & 25 & $7.20(2.55)$ & 60 & $6.83(2.88)$ \\
\hline & $\mathrm{T} / \mathrm{T}$ & 2 & $7.50(0.71)$ & 1 & $8.00(-)$ & 1 & $7.00(-)$ \\
\hline \multirow[t]{3}{*}{ rs4818 } & $\mathrm{C} / \mathrm{C}$ & 340 & $7.45(2.36)$ & 108 & 8.09 (2.33) & 232 & $7.15(2.46)$ \\
\hline & $\mathrm{C} / \mathrm{G}$ & 328 & 7.19 (2.63) & 102 & 7.50 (2.62) & 226 & $7.04(2.63)$ \\
\hline & $\mathrm{G} / \mathrm{G}$ & 85 & $6.98(2.51)$ & 27 & 7.07 (2.56) & 58 & $6.93(2.51)$ \\
\hline \multirow[t]{3}{*}{ rs4680 } & $\mathrm{A} / \mathrm{A}$ & 48 & $7.56(2.61)$ & 19 & 8.63 (2.03) & 29 & $6.86(2.74)$ \\
\hline & $\mathrm{A} / \mathrm{G}$ & 281 & 7.52 (2.49) & 87 & $7.94(2.46)$ & 194 & $7.32(2.49)$ \\
\hline & $\mathrm{G} / \mathrm{G}$ & 424 & 7.09 (2.56) & 131 & $7.44(2.56)$ & 293 & $6.94(2.55)$ \\
\hline
\end{tabular}

insight problem solving only in males. In line with previous studies, the gender difference of the COMT effect is found in many domains, especially this male-specific effect, such as cognition (Harrison and Tunbridge, 2008), prefrontal blood oxygenation-level-dependent activation (Coman et al., 2010), and addiction-like behavior in rats (Tammimäki and Männistö, 2011). The mechanisms underlying the association between insight problem solving and the COMT gene may be related to the DA pathways and the noradrenergic system. COMT metabolizes all catecholamines, including DA and NE (Weinshilboum et al., 1999). Evidence shows that DA may affect insight problem solving through its effects on individuals' working memory and cognitive flexibility (Gilhooly and Fioratou, 2009; Lin et al., 2014). Meanwhile, NE may significantly impact on cognitive flexibility, and therefore improve solving insight problems (Beversdorf et al.,
1999; Hillier et al., 2006; Alexander et al., 2007). Future studies may further investigate levels of DA and NE along with some cognitive abilities at the same time to verify these two possible explanations.

Insight problem solving, measured by close-ended creative tasks, reflects a kind of convergent thinking. According to Guilford (1950), creativity involves two components: divergent thinking and convergent thinking. Divergent thinking refers to open-ended problem solving, making individuals generate multiple ideas or solutions. Previous studies have found that rs737865, rs4680, and rs5993883 of COMT genes were correlated with divergent thinking as well (Zhang et al., 2014a). In the current study, rs4633, rs4680, and rs5993883 of COMT genes were correlated with insight problem solving. These same genetic influences may indicate that divergent thinking and convergent

TABLE 3 | ANCOVA results for the interaction of genotype and gender on insight problem-solving performance.

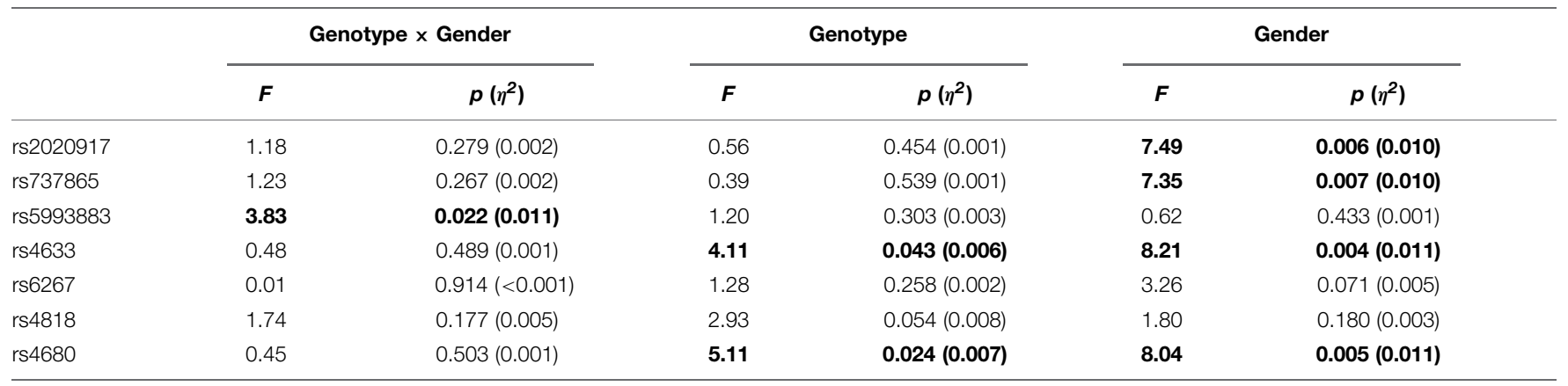

Bolded values means significant effect. 


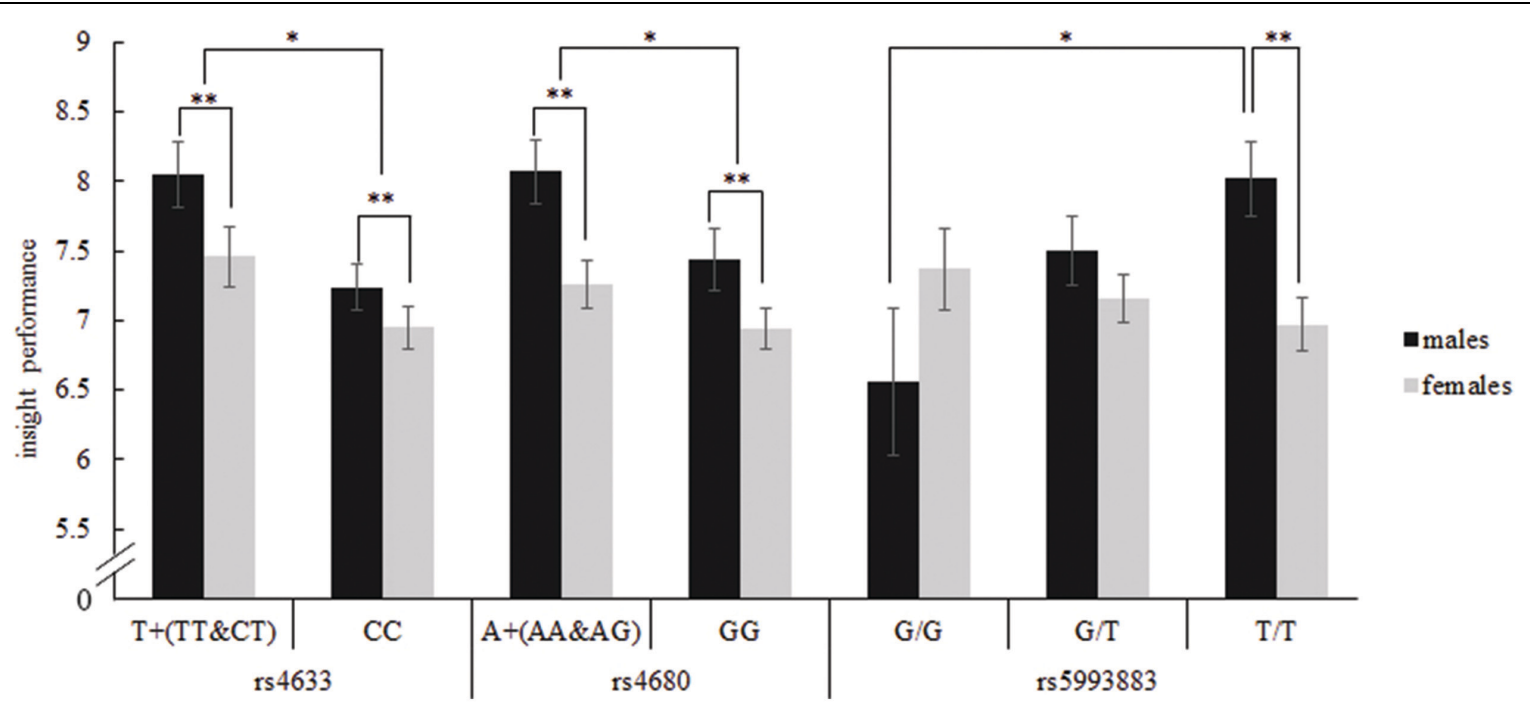

FIGURE 2 | Insight problem-solving performance depending on the interaction of COMT rs4633, rs4680, rs5993883, and gender. For rs4633, T allele carriers had a higher score on insight tasks than CC carriers, and males performed better on insight problems than females. For rs4680, A allele carriers had a higher score on insight tasks than GG carriers, and males performed better on insight tasks than females. For rs5993883, in males, $\Pi 1$ genotype carriers performed better on insight problem solving than GG carriers. Additionally, male carriers of $\Pi$ genotype scored higher on insight tasks than females with $\Pi$. Error bars represent standard error. ${ }^{*} p<0.05,{ }^{* *} p<0.01$.

thinking are related. Previous studies have also supported this from other perspectives. For example, both divergent thinking and insight problem solving benefited from positive mood states (Baas et al., 2008). Moreover, using transcranial direct current stimulation, studies have found that both divergent thinking and insight problem solving have a right hemispheric superiority (Chi and Snyder, 2011; Mayseless and ShamayTsoory, 2015). Some researchers even believed that divergent thinking was the foundation of insight problem solving (Brophy, 1998). However, other studies found that divergent thinking and convergent thinking involves different process (Chermahini and Hommel, 2010; Lin and Lien, 2013). Future studies may further investigate the relationship between divergent thinking and convergent thinking, especially from biological perspectives. In addition, insight problem solving is only one kind of convergent thinking task, and there are other tasks reflecting convergent thinking as well, for instance, the Remote Associates Task (RAT; Mednick, 1962). In fact, previous studies have found that DA is correlated with RAT scores (Chermahini and Hommel, 2010; Ueda et al., 2015). Future studies may investigate the relation between the COMT gene and RAT performance to draw a whole genetic impact picture of convergent thinking, and to further understand two components of creativity - divergent thinking and convergent thinking - from genetic perspectives.

There are limitations of this study. The current study only examined one catecholamine-related gene, the COMT gene, as a genetic influences on insight problem solving. However, there are many other important genes involved in catecholamine transmission that could contribute to insight problem solving, such as DA transporter (DAT1), DA D2 receptor gene (DRD2), DA D4 receptor gene $(D R D 4)$, and monoamine oxidase A gene (MAOA) (Bachner-Melman et al., 2005; Reuter et al.,
2006; Runco et al., 2011; Mayseless et al., 2013; Zhang et al., 2014a,b). Moreover, divergent thinking has been found to have an association with other catecholamine-related genes. For example, carriers with 7R allele of DA receptor D4 gene (DRD4) performed worse in divergent thinking (Mayseless et al., 2013). Future studies may consider other single polymorphisms effects as well as gene-gene interaction effects on insight problem solving, to further understand the genetic impact on insight problem solving and creativity. Moreover, although participants were not asked whether they experienced an "aha" moment of insight, we adopted pure insight problem tasks that can only be solved through an insight process (Dow and Mayer, 2004; DeYoung et al., 2008). Future studies may add this inquiry to confirm the association between the COMT gene and insight.

\section{CONCLUSION}

The present study provides the first evidence for the COMT gene as the genetic influences on insight problem solving, although the results should be interpreted with great caution. Despite the underlying mechanisms are still unclear, the current study demonstrated that the COMT gene does indeed contributes to insight problem solving, and its effects are modulated by gender. This research may promote our understanding of the evolutionary and biological roots of insight problem solving.

\section{AUTHOR CONTRIBUTIONS}

WJ, YS contributed to the conception and design of the work. WJ, SS collected and analyzed the data. WJ, SS, YS contributed to the writing of the manuscript. 


\section{FUNDING}

This research was supported by the National Natural Science Foundation of China (Grant Nos. 31170995, 31371040, 31571134).

\section{REFERENCES}

Alexander, J. K., Hillier, A., Smith, R. M., Tivarus, M. E., and Beversdorf, D. Q. (2007). Beta-adrenergic modulation of cognitive flexibility during stress. J. Cogn. Neurosci. 19, 468-478. doi: 10.1162/jocn.2007.19.3.468

Ashby, F. G., Isen, A. M., and Turken, A. U. (1999). A neuropsychological theory of positive affect and its influence on cognition. Psychol. Rev. 106, 529-550. doi: 10.1037/0033-295X.106.3.529

Baas, M., De Dreu, C. K., and Nijstad, B. A. (2008). A meta-analysis of 25 years of mood-creativity research: hedonic tone, activation, or regulatory focus? Psychol. Bull. 134, 779-806. doi: 10.1037/a0012815

Bachner-Melman, R., Dina, C., Zohar, A. H., Constantini, N., Lerer, E., Hoch, S., et al. (2005). AVPR1a and SLC6A4 gene polymorphisms are associated with creative dance performance. PLoS Genet. 1:e42. doi: 10.1371/journal.pgen.0010042

Barnett, J. H., Heron, J., Ring, S. M., Golding, J., Goldman, D., Xu, K., et al. (2007a). Gender-specific effects of the catechol-o-methyltransferase val 108/158 met polymorphism on cognitive function in children. Am. J. Psychiatry 164, 142-149. doi: 10.1176/ajp.2007.164.1.142

Barnett, J. H., Jones, P. B., Robbins, T. W., and Müller, U. (2007b). Effects of the catechol-O-methyltransferase Val158Met polymorphism on executive function: a meta-analysis of the Wisconsin Card Sort Test in schizophrenia and healthy controls. Mol. Psychiatry 12, 502-509. doi: 10.1038/sj.mp.4001973

Beversdorf, D. Q., Hughes, J. D., Steinberg, B. A., Lewis, L. D., and Heilman, K. M. (1999). Noradrenergic modulation of cognitive flexibility in problem solving. Neuroreport 10, 2763-2767. doi: 10.1097/00001756-199909090-00012

Bowden, E. M., Jung-Beeman, M., Fleck, J., and Kounios, J. (2005). New approaches to demystifying insight. Trends Cogn. Sci. 9, 322-328. doi: 10.1016/j.tics.2005.05.012

Brophy, D. R. (1998). Understanding, measuring, and enhancing individual creative problem-solving efforts. Creat. Res. J. 11, 123-150. doi: 10.1207/s15326934crj1102_4

Cai, D. J., Mednick, S. A., Harrison, E. M., Kanady, J. C., and Mednick, S. C. (2009). REM, not incubation, improves creativity by priming associative networks. Proc. Natl. Acad. Sci. U.S.A. 106, 10130-10134. doi: 10.1073/pnas.0900271106

Chen, J., Lipska, B. K., Halim, N., Ma, Q. D., Matsumoto, M., Melhem, S., et al. (2004). Functional analysis of genetic variation in catechol-O-methyltransferase (COMT): effects on mRNA, protein, and enzyme activity in postmortem human brain. Am. J. Hum. Genet. 75, 807-821. doi: 10.1086/425589

Chermahini, S. A., and Hommel, B. (2010). The (b) link between creativity and dopamine: spontaneous eye blink rates predict and dissociate divergent and convergent thinking. Cognition 115, 458-465. doi: 10.1016/j.cognition.2010.03.007

Chi, R. P., and Snyder, A. W. (2011). Facilitate insight by non-invasive brain stimulation. PLoS ONE 6:e16655. doi: 10.1371/journal.pone.0016655

Chiu, F. C., Chen, H. C., Hsu, C. C., Wu, H. Y., and Cho, S. L. (2008). The impact of implicit and explicit factors on the performance of creativity tasks. Chin. J. Psychol. 50, 125-145. doi: 10.6129/CJP

Chu, Y., and MacGregor, J. N. (2011). Human performance on insight problem solving: a review. J. Probl. Solving 3, 119-150. doi: 10.7771/1932-6246.1094

Chudasama, Y., and Robbins, T. W. (2006). Functions of frontostriatal systems in cognition: comparative neuropsychopharmacological studies in rats, monkeys and humans. Biol. Psychol. 73, 19-38. doi: 10.1016/j.biopsycho.2006. 01.005

Coman, I. L., Gnirke, M. H., Middleton, F. A., Antshel, K. M., Fremont, W., Higgins, A. M., et al. (2010). The effects of gender and catechol O-methyltransferase (COMT) Val108/158Met polymorphism on emotion regulation in velo-cardio-facial syndrome (22q11. 2 deletion syndrome): an fMRI study. Neuroimage 53, 1043-1050. doi: 10.1016/j.neuroimage.2010. 01.094

\section{ACKNOWLEDGMENTS}

We appreciate all the participants involved in this study for their enthusiastic support and participation. We appreciate our lab members who provided invaluable discussions.

Cools, R., and D'Esposito, M. (2011). Inverted-U-shaped dopamine actions on human working memory and cognitive control. Biol. Psychiatry 69, e113-e125. doi: 10.1016/j.biopsych.2011.03.028

Davis, K. L., Kahn, R. S., Ko, G., and Davidson, M. (1991). Dopamine in schizophrenia: a review and reconceptualization. Am. J. Psychiatry 148, 1474-1486. doi: 10.1176/ajp.148.11.1474

DeYoung, C. G., Flanders, J. L., and Peterson, J. B. (2008). Cognitive abilities involved in insight problem solving: an individual differences model. Creat. Res. J. 20, 278-290. doi: 10.1080/10400410802278719

Dow, G. T., and Mayer, R. E. (2004). Teaching students to solve insight problems: evidence for domain specificity in creativity training. Creat. Res. J. 16, 389-398. doi: 10.1080/10400410409534550

Egan, M. F., Goldberg, T. E., Kolachana, B. S., Callicott, J. H., Mazzanti, C. M., Straub, R. E., et al. (2001). Effect of COMT Val108/158 Met genotype on frontal lobe function and risk for schizophrenia. Proc. Natl. Acad. Sci. U.S.A. 98, 6917-6922. doi: 10.1073/pnas.111134598

Fleck, J. I. (2008). Working memory demands in insight versus analytic problem solving. Eur. J. Cogn. Psychol. 20, 139-176. doi: 10.1080/095414406010 16954

Foerder, P., Galloway, M., Barthel, T., Moore, D. E. III, and Reiss, D. (2011). Insightful problem solving in an Asian elephant. PLOS ONE 6:e23251. doi: 10.1371/journal.pone.0023251

Folley, B. S., Doop, M. L., and Park, S. (2003). Psychoses and creativity: is the missing link a biological mechanism related to phospholipids turnover? Prostaglandins Leukot. Essent. Fatty Acids 69, 467-476. doi: 10.1016/j.plefa.2003.08.019

Friedman, R. S., and Förster, J. (2005). Effects of motivational cues on perceptual asymmetry: implications for creativity and analytical problem solving. J. Pers. Soc. Psychol. 88, 263-275. doi: 10.1037/0022-3514.88.2.263

Gilhooly, K. J., and Fioratou, E. (2009). Executive functions in insight versus noninsight problem solving: an individual differences approach. Think Reason. 15, 355-376. doi: 10.1080/13546780903178615

Gilhooly, K. J., and Murphy, P. (2005). Differentiating insight from non-insight problems. Think Reason. 11, 279-302. doi: 10.1080/13546780442000187

Goldberg, T. E., Egan, M. F., Gscheidle, T., Coppola, R., Weickert, T., Kolachana, B. S., et al. (2003). Executive subprocesses in working memory: relationship to catechol-O-methyltransferase Val158Met genotype and schizophrenia. Arch. Gen. Psychiatry 60, 889-896. doi: 10.1001/archpsyc.60.9.889

Guilford, J. P. (1950). Creativity. Am. Psychol. 5, 444-454. doi: 10.1037/h0063487

Handoko, H. Y., Nyholt, D. R., Hayward, N. K., Nertney, D. A., Hannah, D. E., Windus, L. C., et al. (2005). Separate and interacting effects within the catechol-O-methyltransferase (COMT) are associated with schizophrenia. Mol. Psychiatry 10, 589-597. doi: 10.1038/sj.mp.4001606

Harrison, P. J., and Tunbridge, E. M. (2008). Catechol-O-methyltransferase (COMT): a gene contributing to sex differences in brain function, and to sexual dimorphism in the predisposition to psychiatric disorders. Neuropsychopharmacology 33, 3037-3045. doi: 10.1038/sj.npp.1301543

Heilman, K. M., Nadeau, S. E., and Beversdorf, D. O. (2003). Creative innovation: possible brain mechanisms. Neurocase 9, 369-379. doi: 10.1076/neur.9.5.369.16553

Hillier, A., Alexander, J. K., and Beversdorf, D. Q. (2006). The effect of auditory stressors on cognitive flexibility. Neurocase 12, 228-231. doi: $10.1080 / 13554790600878887$

Isen, A. M., Daubman, K. A., and Nowicki, G. P. (1987). Positive affect facilitates creative problem solving. J. Pers. Soc. Psychol. 52, 1122-1131. doi: 10.1037/00223514.52.6.1122

Karimi, Z., Windmann, S., Güntürkün, O., and Abraham, A. (2007). Insight problem solving in individuals with high versus low schizotypy. J. Res. Pers. 41, 473-480. doi: 10.1016/j.jrp.2006.03.008

Köhler, W. (1925). The Mentality of Apes. New York, NY: Vintage Books. 
Kounios, J., and Beeman, M. (2014). The cognitive neuroscience of insight. Annu. Rev. Psychol. 65, 71-93. doi: 10.1146/annurev-psych-010213-1 15154

Lachman, H. M., Papolos, D. F., Saito, T., Yu, Y. M., Szumlanski, C. L., and Weinshilboum, R. M. (1996). Human catechol-O-methyltransferase pharmacogenetics: description of a functional polymorphism and its potential application to neuropsychiatric disorders. Pharmacogenetics 6, 243-250. doi: 10.1097/00008571-199606000-00007

Lee, C. S., and Therriault, D. J. (2013). The cognitive underpinnings of creative thought: a latent variable analysis exploring the roles of intelligence and working memory in three creative thinking processes. Intelligence 41, 306-320. doi: 10.1016/j.intell.2013.04.008

Lin, W. L., and Lien, Y. W. (2013). The different role of working memory in open-ended versus closed-ended creative problem solving: a dual-process theory account. Creat. Res. J. 25, 85-96. doi: 10.1080/10400419.2013.7 52249

Lin, W. L., Tsai, P. H., Lin, H. Y., and Chen, H. C. (2014). How does emotion influence different creative performances? The mediating role of cognitive flexibility. Cogn. Emot. 28, 834-844. doi: 10.1080/02699931.2013.8 54195

Ma, X., Sun, J., Yao, J., Wang, Q., Hu, X., Deng, W., et al. (2007). A quantitative association study between schizotypal traits and COMT, PRODH and BDNF genes in a healthy Chinese population. Psychiatry Res. 153, 7-15. doi: 10.1016/j.psychres.2007.02.003

Mayseless, N., and Shamay-Tsoory, S. G. (2015). Enhancing verbal creativity: modulating creativity by altering the balance between right and left inferior frontal gyrus with tDCS. Neuroscience 291, 167-176. doi: 10.1016/j.neuroscience.2015.01.061

Mayseless, N., Uzefovsky, F., Shalev, I., Ebstein, R. P., and Shamay-Tsoory, S. G. (2013). The association between creativity and $7 \mathrm{R}$ polymorphism in the dopamine receptor D4 gene (DRD4). Front. Hum. Neurosci. 7:502. doi: 10.3389/fnhum.2013.00502

Mednick, S. (1962). The associative basis of the creative process. Psychol. Rev. 69, 220-232. doi: 10.1037/h0048850

Reuter, M., Roth, S., Holve, K., and Hennig, J. (2006). Identification of first candidate genes for creativity: a pilot study. Brain Res. 1069, 190-197. doi: 10.1016/j.brainres.2005.11.046

Runco, M. A. (2004). Creativity. Annu. Rev. Psychol. 55, 657-687. doi: 10.1146/annurev.psych.55.090902.141502

Runco, M. A., Noble, E. P., Reiter-Palmon, R., Acar, S., Ritchie, T., and Yurkovich, J. M. (2011). The genetic basis of creativity and ideational fluency. Creat. Res. J. 23, 376-380. doi: 10.1080/10400419.2011.621859

Shettleworth, S. J. (2012). Do animals have insight, and what is insight anyway? Can. J. Exp. Psychol. 66, 217-226. doi: 10.1037/a0030674
Simonton, D. K. (2003). Scientific creativity as constrained stochastic behavior: the integration of product, person, and process perspectives. Psychol. Bull. 129, 475-494. doi: 10.1037/0033-2909.129.4.475

Smith, R. W., and Kounios, J. (1996). Sudden insight: all-or-none processing revealed by speed-accuracy decomposition. J. Exp. Psychol. Learn. Mem. Cogn. 22, 1443-1462. doi: 10.1037/0278-7393.22.6.1443

Sternberg, R. J., and Davidson, J. E. (eds) (1995). The Nature of Insight. Cambridge: MIT Press.

Subramaniam, K., Kounios, J., Parrish, T. B., and Jung-Beeman, M. (2009). A brain mechanism for facilitation of insight by positive affect. J. Cogn. Neurosci. 21, 415-432. doi: 10.1162/jocn.2009.21057

Tammimäki, A., and Männistö, P. T. (2011). Effect of genetic modifications in the synaptic dopamine clearance systems on addiction-like behaviour in mice. Basic Clin. Pharmacol. Toxicol. 108, 2-8. doi: 10.1111/j.1742-7843.2010.00647.x

Ueda, Y., Tominaga, A., Kajimura, S., and Nomura, M. (2015). Spontaneous eye blinks during creative task correlate with divergent processing. Psychol. Res. doi: 10.1007/s00426-015-0665-x [Epub ahead of print].

Velázquez, J. A., Segal, N. L., and Horwitz, B. N. (2015). Genetic and environmental influences on applied creativity: a reared-apart twin study. Pers. Individ. Differ. 75, 141-146. doi: 10.1016/j.paid.2014.11.014

Weinshilboum, R. M., Otterness, D. M., and Szumlanski, C. L. (1999). Methylation pharmacogenetics: catechol O-methyltransferase, thiopurine methyltransferase, and histamine N-methyltransferase. Annu. Rev. Pharmacol. Toxicol. 39, 19-52. doi: 10.1146/annurev.pharmtox.39.1.19

Witte, A. V., and Flöel, A. (2012). Effects of COMT polymorphisms on brain function and behavior in health and disease. Brain Res. Bull. 88, 418-428. doi: 10.1016/j.brainresbull.2011.11.012

Zhang, S., Zhang, M., and Zhang, J. (2014a). Association of COMT and COMTDRD2 interaction with creative potential. Front. Hum. Neurosci. 8:216. doi: 10.3389/fnhum.2014.00216

Zhang, S., Zhang, M., and Zhang, J. (2014b). An exploratory study on DRD2 and creative potential. Creat. Res. J. 26, 115-123. doi: $10.1080 / 10400419.2014 .874267$

Conflict of Interest Statement: The authors declare that the research was conducted in the absence of any commercial or financial relationships that could be construed as a potential conflict of interest.

Copyright (c) 2015 Jiang, Shang and Su. This is an open-access article distributed under the terms of the Creative Commons Attribution License (CC BY). The use, distribution or reproduction in other forums is permitted, provided the original author(s) or licensor are credited and that the original publication in this journal is cited, in accordance with accepted academic practice. No use, distribution or reproduction is permitted which does not comply with these terms. 